\title{
Pola Pendidikan Karakter Religius dalam Pembelajaran Daring SMP Plus Citra Madhinatul IImi (CMI)
}

\author{
Akhmad Syakir \\ (Corresponding Author) \\ Universitas Muhammadiyah Banjarmasin \\ Email: ahmadsyakir02@gmail.com \\ Jamiatul Hamidah \\ Universitas Muhammadiyah Banjarmasin \\ Email:midah.beswan@gmail.com \\ Istiqamah \\ Universitas Muhammadiyah Banjarmasin \\ Email: iscutebibeh@gmail.com
}

\begin{abstract}
APA Citation: Syakir, A., Hamidah, J., \& Istiqamah, I. (2021). Pola Pendidikan Karakter Religius dalam Pembelajaran Daring SMP Plus Citra Madhinatul IImi (CMI). Silampari Bisa: Jurnal Penelitian Pendidikan Bahasa Indonesia, Daerah, dan Asing, 4(2), 478-488. https://doi.org/10.31540/silamparibisa.v4i2.1350
\end{abstract}

\begin{abstract}
Abstrak
Penelitian ini bertujuan untuk mengetahui pola pendidikan karakter religius terhadap siswa yang dilaksanakan di SMP Plus Citra Madhinatul IImi (CMI) terutama dalam pembelajaran daring. Penelitian menggunakan pendekatan kualitatif melalui metode stud kasus. Sumber data penelitian diambil dari wawancara kepada informan yang terdiri atas kepala sekolah, guru kelas, guru bahasa Indonesia, guru bahasa Inggris, dan guru Matematika. Data penelitian diambil melalui wawancara secara mendalam kepada seluruh informan. Hasil penelitian menunjukkan bahwa penanaman nilai pendidikan karakter terhadap siswa SMP Plus Citra Madhinatul IImi (CMI) tetap bisa dilakukan dalam pembelajaran daring. Nilai-nilai karakter yang ditanamkan di sekolah yaitu nilai religius, nasionalisme, integritas, mandiri, dan gotong-royong. Pola pendidikan karakter religius dalam pembelajaran daring dilakukan dengan menggunakan berbagai media yang mudah diakses serta kerja sama antara orang tua dengan guru dalam hal pengawasan terhadap siswa.
\end{abstract}

Kata kunci: pola pendidikan, karakter religius, pembelajaran daring, SMP 


\title{
Religious Character Education Patterns in Online Learning for SMP Plus Citra Madhinatul IImi (CMI)
}

\begin{abstract}
This study aims to determine the pattern of religious character education for students carried out at SMP Plus Citra Madhinatul IImi (CMI), especially in online learning. The research uses a qualitative approach through the case study method. Sources of research data were taken from interviews with informants consisting of principals, classroom teachers, Indonesian language teachers, English teachers, and Mathematics teachers. Research data were taken through in-depth interviews with all informants. The results showed that the cultivation of character education values for SMP Plus Citra Madhinatul IImi (CMI) students can still be done in online learning. Character values that are instilled in schools are religious values, nationalism, integrity, independence, and mutual cooperation. The pattern of religious character education in online learning is carried out using various easily accessible media and collaboration between parents and teachers in terms of supervision of students.
\end{abstract}

Keywords: education pattern, religious character, online learning, junior high school

\section{A. Pendahuluan}

Dalam usaha mendidik siswa yang berkarakter, terdapat delapan belas nilainilai pendidikan karakter yang mesti ditanamkan oleh seorang guru. Delapan belas pesan karakter tersebut adalah: religius, jujur, toleransi, disiplin, kerja keras, kreatif, mandiri, demokratis, rasa ingin tahu, semangat kebangsaan, cinta tanah air, menghargai prestasi, bersahabat/komunikatif, cinta damai, gemar membaca, peduli lingkungan, peduli sosial, tanggung jawab (Hamirul, 2021). Pada dasarnya konsep pendidikan karakter bukanlah sesuatu yang baru dalam konsep pendidikan di Indonesia. Buktinya, para pendiri negeri ini secara nyata telah menuangkan nilainilai karakter tersebut sebagaimana terlihat jelas pada seluruh sila-sila Pancasila sebagai dasar negara.

Menanamkan nilai-nilai karakter terhadap siswa sebagaimana telah dirumuskan dalam Kurikulum 2013 merupakan langkah awal untuk memperbaiki tujuan Pendidikan di Indonesia (Widyastuti dkk., 2021). Begitu juga penanaman pendidikan karakter ternyata mampu mendidik siswa yang unggul dari aspek pengetahuan, cerdas secara emosional, dan kuat dalam keperibadian (Lickona, 2018).

Menurut beberapa penelitian terdahulu seperti yang dilakukan oleh (Gunawan, Suyitno, \& Supriyadi, 2018) dinyatakan bahwa Pendidikan di Indonesia secara umum masih berorientasikan kepada hasil ujian (exam oriented). Oleh karena itu, sudah saatnya sistem pendidikan Indonesia direformasi karena belum mampu menjawab kebutuhan zaman. Merujuk kepada hasil penelitian dan pendapat tersebut, maka tentu perlu pembuktian secara empirik tentang bagaimana penerapan pendidikan karakter di sekolah. Pada masa pandemi Covid19 saat ini, pemerintah menganjurkan pembelajaran secara daring, sehingga penanaman karakter oleh guru maupun pihak sekolah memiliki tantangan tersendiri dalam penerapannya. Dalam proses pembelajaran daring penanaman karakter tetap dilaksanakan agar dapat mengatasi asumsi dan ancaman kepada generasi 
Akhmad Syakir, Jamiatul Hamidah, Istiqamah

Pola Pendidikan Karakter Religius dalam Pembelajaran Daring SMP Plus Citra

Madhinatul IImi (CMI)

sekarang yang cenderung rapuh, mudah emosi, dan kehilangan karakter sebagai generasi.

SMP Plus Citra Madhitanul IImi (CMI) Banjarmasin merupakan salah satu sekolah berbasis penanaman nilai karakter kepada siswa. Sekolah ini mengunggulkan nilai karakter islami, yang diajarkan kepada siswa dalam kegiatan akademik maupun di luar kegiatan akademik. Sebagai contoh, kepala sekolah menerapkan kebijakan setiap bulan siswa harus khatam membaca Al Quran. Pembiasaan ini juga harus dilakukan oleh guru, dengan pengawasan bersilang antara kepala sekolah, guru, maupun siswa. Guru diwajibkan memberikan contoh/tauladan bagi siswa agar mengkhatamkan membaca Al Quran setiap bulan. Jika tidak mencapai target, maka akan dievaluasi terkait kendala yang dihadapi dan pada bulan berikutnya harus diperbaiki.

Berdasarkan informasi awal di atas, peneliti tertarik untuk dapat mendeskripsikan bagaimana pola penanaman karakter dalam pembelajaran media daring di SMP Plus CMI Banjarmasin. Untuk memperoleh data, peneliti melakukan wawancara kepada kepala sekolah, guru kelas, guru Bahasa Indonesia, guru Bahasa Inggris dan guru Matematika.

Penelitian serupa pernah dilakukan oleh Santika (2020) tentang pelaksanaan pendidikan karakter pada pembelajaran daring. Tujuan penelitian ini adalah memberikan gambaran inovasi guru dalam memproses pembelajaran di rumah agar tetap menyenangkan dan mampu mengakomodir tujuan pembelajaran terutama dalam pendidikan karakter bangsa. Hasil penelitian tersebut menyebutkan bahwa untuk menanamkan pendidikan karakter dalam pembelajaran daring guru harus memiliki strategi implementasi pendidikan karakter melalui multiple intelligences berbasis portofolio dengan diitegrasikan pada mata pelajaran. Hal ini sebagai suatu upaya dalam proses pembelajaran untuk dapat mengembangkan life skill atau kecakapan peserta didik.

Selain itu, Putri (2020) melakukan penelitian terkait pendidikan karakter siswa melalui pembelajaran Bahasa Indonesia. Berdasarkan hasil penelitian disimpulkan bahwa pendidikan karakter merupakan satu hal yang sangat penting karena menjadi proses pemberian tuntunan kepada peserta didik untuk menjadi manusia seutuhnya yang berkarakter dalam dimensi hati, pikir, raga, serta rasa dan karsa. Melalui metodologi dan strategi pendidikan karakter yang dilakukan oleh pengajar, berguna menciptakan pendidikan karakter yang efektif. Sejalan dengan itu, Atmazaki, Agustina, \& Indriyani (2021) menyatakan bahwa pendidikan di abad ke21 saat ini menuntut siswa untuk menjadi cerdas dan berkarakter. Namun, pada masa pandemi, tantangan terbesar bagi guru adalah tetap mengajarkan pendidikkan karakter di sekolah melalui pembelajaran daring. Di antara sekolah yang melaksanakan pembelajaran daring yaitu SMP Plus Citra Madinatul IImi Banjarmasin. Penelitian ini bertujuan untuk memberikan gambaran bagaimana sekolah tersebut menerapkan pendidikan karakter melalui media daring. Manfaat yang diharapkan dari hasil penelitian ini adalah guru memiliki pengetahuan dan kemampuan mengintegrasikan penguatan karakter siswa melalui kegiatan intrakurikuler, ekstrakurikuler, dan nonkurikuler dalam pembelajaran Bahasa Indonesia. 
Akhmad Syakir, Jamiatul Hamidah, Istiqamah

Pola Pendidikan Karakter Religius dalam Pembelajaran Daring SMP Plus Citra

Madhinatul IImi (CMI)

\section{B. Metode Penelitian}

Penelitian ini menggunakan pendekatan kualitatif dengan metode studi kasus (case study method). Yin (2012) menjelaskan bahwa metode ini tepat digunakan apabila peneliti ingin melihat dan mengeksplorasi hasil dari sebuah program atau kegiatan yang telah dilaksanakan. Sedangkan Bungin (2005) menyatakan desain penelitian seperti ini dapat membantu peneliti memahami permasalahan secara dalam dan kompleks. Sumber data penelitian diperoleh dari wawancara dengan kepala sekolah, guru kelas, guru Bahasa Indonesia, guru Bahasa Inggris dan guru Matematika. Teknik pengumpulan data adalah melakukan wawancara dengan kepala sekolah dan guru mata pelajaran, serta survei melalui pembagian angket kepada siswa. Instrumen yang digunakan adalah pedoman wawancara yang telah divalidasi ahli. Data dianalisis dengan mengklasifikasikan bentuk penerapan pendidikan karakter melalui media daring, kemudian dideskripsikan berdasarkan kategori yang ditemukan.

Menurut Anggito \& Setiawan (2010) pemilihan informan setidaknya harus mempunyai empat kategori, yaitu: (1) memahami dengan baik permasalahan yang diteliti; (2) masih aktif dalam bidang yang diteliti; (3) mempunyai waktu untuk memberikan informasi kepada peneliti, dan (4) memberikan informasi sesuai dengan fakta yang terjadi di lapangan.

\section{Hasil Penelitian dan Pembahasan \\ 1. Hasil Penelitian}

Sekolah Islam SMP Plus Madinatul Banjarbaru biasanya menerapkan pendidikan karakter kepada siswa saat pembelajaran tatap muka, namun selama pandemi COVID-19, sekolah harus menerapkan pendidikan karakter melalui pembelajaran online. SMP Plus CMI merupakan sekolah menengah pertama yang bercirikan Islam, berada di bawah naungan Yayasan Citra Baburrahman Madinatul Ilmi Banjarbaru. Sekolah ini beralamat di Jln. Ahmad Yani Km. 17,5 Kota Citra Graha, Desa/ Kelurahan Landasan Ulin Barat, Kecamatan Liang Anggang, Kabupaten/Kota Banjarbaru Provinsi Kalimantan Selatan. Status kepemilikan bangunan sekolah adalah milik Yayasan Citra Baburrahman Madinatul IImi Banjarbaru. Status sekolah adalah swasta dan melaksanakan pendidikan dengan sistem Fullday School (Senin s.d. Jumat, pukul 07.45-16.30). Sekolah ini berdiri pada tahun 2010 dan mulai beroperasi di tahun yang sama.

Adapun Visi dan Misi dari SMP Plus Citra Madhinatul IImi adalah sebagai berikut. Visi; "Terwujudnya Lulusan yang Berakhlaq Mulia, Islami, Cerdas dan Kompetitif serta Peduli Lingkungan". Misi SMP Plus CMI adalah:

1) Menyelenggarakan pendidikan yang berkualitas berwawasan kebangsaan dan agamis.

2) Mengembangkan potensi peserta didik dalam kemampuan, bakat, minat dan bersikap mandiri.

3) Memberdayakan sumber daya lingkungan/kearifan lokal berwawasan IPTEK, seni budaya, dan berdaya saing.

4) Memberdayakan nilai-nilai spiritual Islami, ilmu amaliah, dan amal ilmiah.

5) Meningkatkan tata kelola manajemen yang dilandasi prinsip amanah dan transparan.

6) Meningkatkan kepedulian warga sekolah terhadap lingkungan. 
Akhmad Syakir, Jamiatul Hamidah, Istiqamah

Pola Pendidikan Karakter Religius dalam Pembelajaran Daring SMP Plus Citra Madhinatul IImi (CMI)

7) Mengembangkan sekolah islami yang berwawasan lingkungan.

8) Mewujudkan suasana belajar yang segar dan kondusif.

Di samping itu, tujuan SMP Plus CMI adalah: 1) meningkatkan prestasi akademik peserta didik sesuai kemampuan, bakat dan minat; 2) menanamkan nilai keimanan dan ketakwaan (IMTAQ) menjadi generasi Islam, berperilaku akhlakul karimah; 3) menumbuhkembangkan rasa cinta tanah air dan berwawasan kebangsaan; 4) memberikan kompetensi dasar ICT, seni budaya sesuai kearifan lokal dalam dinamika global; 5) menjabarkan nilai-nilai profesionalisme yang tercermin dalam manajemen yang efektif, efisien, transparan, dan akuntabel bagi public; 6) menjadi sekolah pelopor lingkungan, bersih, indah, dan asri; 7) menjadikan warga sekolah yang peduli terhadap lingkungan; dan 8) membiasakan siswa mengenal lingkungan dengan pembelajaran berbasis lingkungan.

Berdasarkan studi pendahuluan melalui wawancara dengan kepala sekolah, SMP Plus CMI memiliki motto "Berakhlak, Jujur, Bagus Bagus Bagus" sehingga ini adalah pondasi awal peserta didik di SMP tersebut. Ketika pembelajaran tatap muka, penanaman karakter akan mudah diimplementasikan dalam kehidupan sehari-hari di sekolah. Namun, tantangannya menjadi lebih besar ketika semua pembelajaran di masa pandemi Covid-19 sekarang ini yang berubah menjadi pembelajaran daring. Tentunya sekolah harus mempunyai strategi khusus dalam pola penanaman karakter dalam pembelajaran daring.

Menurut Kamus Besar Bahasa Indonesa Indonesia, pola berarti bentuk atau struktur yang tetap sehingga dalam penelitian ini, berusaha menemukan bentuk atau struktur seperti apa yang digunakan dalam pembelajaran di sekolah terutama dalam penanaman karakter. Beberapa ahli mengemukakan pendapat mereka yang berkaitan dengan pendidikan karakter. Diantaranya menurut Ali (2018) secara teori pembentukan karakter anak dimulai dari usia 0-8 tahun. Artinya di masa usia tersebut karakter anak masih dapat berubah-ubah bergantung dari pengalaman hidupnya. Oleh karena itu, membentuk karakter anak harus dimulai sedini mungkin bahkan sejak anak itu dilahirkan, karena berbagai pengalaman yang dilalui oleh anak semenjak perkembangan pertamanya, mempunyai pengaruh yang besar. Berbagai pengalaman ini berpengaruh dalam mewujudkan apa yang dinamakan dengan pembentukan karakter diri secara utuh.

Pembentukan karakter pada diri anak memerlukan suatu tahapan yang dirancang secara sistematis dan berkelanjutan. Sebagai individu yang sedang berkembang, anak memiliki sifat suka meniru tanpa mempertimbangkan baik atau buruk. Hal ini didorong oleh rasa ingin tahu dan ingin mencoba sesuatu yang diminati, yang kadang muncul secara spontan. Sikap jujur yang menunjukkan kepolosan seorang anak merupakan ciri yang juga dimiliki anak. Akhirnya sifat unik menunjukkan bahwa anak merupakan sosok individu yang kompleks yang memiliki perbedaan dengan individu lainnya.

Pembentukan karakter yang dilakukan di sekolah mempunyai fungsi untuk menumbuhkan kesadaran diri. Kesadaran diri merupakan proses internalisasi dari informasi yang diterima yang pada saatnya menjadi nilai-nilai yang diyakini kebenarannya dan diwujudkan menjadi perilaku keseharian. Oleh karena itu, walaupun kesadaran diri lebih merupakan sikap, namun diperlukan kecakapan untuk menginternalisasi informasi menjadi nilai-nilai dan kemudian mewujudkan menjadi perilaku keseharian.

Silampari Bisa: Jurnal Penelitian Pendidikan Bahasa Indonesia, Daerah, dan Asing Vol. 4, No. 2, 2021 
Akhmad Syakir, Jamiatul Hamidah, Istiqamah

Pola Pendidikan Karakter Religius dalam Pembelajaran Daring SMP Plus Citra Madhinatul IImi (CMI)

Penanaman nilai karakter di sekolah saat ini yang digaungkan oleh pemerintah Indonesia yakni program Penguatan Pendidikan Karakter (PPK) dimana program ini bagaimana menumbuhkan nilai-nilai utama karakter kepada siswa. Berikut gambar alur kristalisasi nilai-nilai PPK.

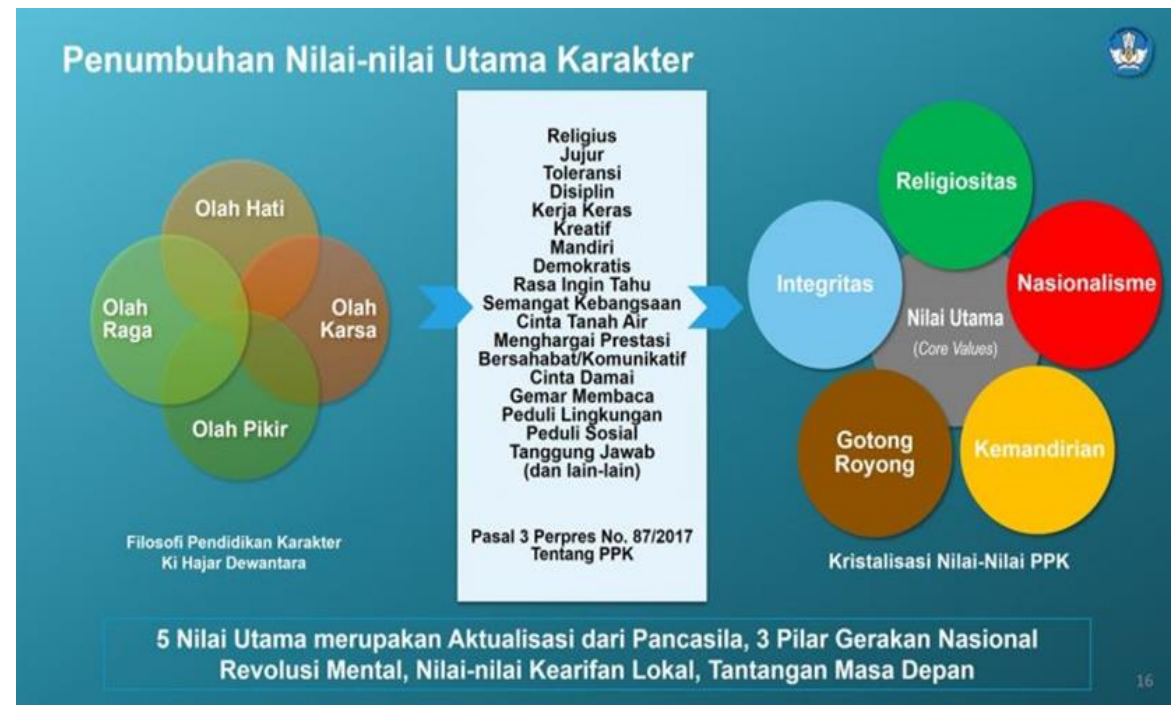

Gambar 1. Alur Kristalisasi Nilai-Nilai PPK

Dari gambar di atas sekolah diharapkan siswa mampu menerapkan atau mengimplementasikan lima nilai-nilai karakter yaitu: 1) nasionalisme, 2) religiusitas, 3) kemandirian, 4) integritas, dan 5) gotong royong. SMP PLUS Citra Madhinatul IImi (CMI) terus menerapkan penanaman nilai-nilai karakter dalam pembelajaran tatap mukanya, sehingga lima karakter dalam Penguatan Pendidikan Karakter (PPK) tersebut sudah berjalan dengan baik dan selaras dalam proses pembelajaran. Di masa pandemi ini, sekolah berusaha untuk tetap menjalankan penanaman nilai karakter tersebut melalui media daring.

Media yang digunakan dalam proses pembelajaran jarak jauh lebih dikenal dengan namanya media daring. Media daring yang banyak digunakan untuk pembelajaran adalah WhatsApp, Zoom Meeting Room, Google Meet, dan Google Classroom. Selain itu, banyak juga media atau aplikasi lain yang digunakan seperti Youtube, Quizez, K-Hoot, dan lain sebagainya.

\section{Pembahasan}

Dari hasil wawancara diperoleh data bahwa nilai-nilai karakter yang ditanamkan di sekolah yaitu nilai yaitu nilai religius, nasionalisme, integritas, mandiri, dan gotong-royong. Hal ini sejalan dengan penelitian Santika (2020) bahwa untuk menanamkan pendidikan karakter dalam pembelajaran daring guru harus memiliki strategi implementasi pendidikan karakter. Pola yang dilakukan sama seperti tatap muka, yang berbeda masa ini sekolah menggunakan media daring atau aplikasi sebagai sarana komunikasi dan pemantauan selama proses pembelajaran. Dalam proses ini sekolah mengedepankan komunikasi bukan hanya kepada siswa, tetapi juga menjalin komunikasi yang baik dengan para orang tua/wali siswa. Hal ini dilakukan untuk terus melakukan pengawasan terhadap 
Akhmad Syakir, Jamiatul Hamidah, Istiqamah

Pola Pendidikan Karakter Religius dalam Pembelajaran Daring SMP Plus Citra

Madhinatul IImi (CMI)

pembelajaran dan penanaman nilai karakter kepada siswa. Jika tahun sebelumnya pada pembelajaran tatap muka guru menjadi tauladan langsung bagi siswa dalam pembentukan sikap positif, maka pada pembelajaran daring guru lebih banyak melakukan pengawasan kepada siswa.

Pengawasan terhadap siswa, tidak terlepas dari peran orang tua yang turut bekerja sama dalam pengawasan siswa selama pembelajaran daring. Dalam pembelajaran daring, peran orang tua sangat diharapkan pihak sekolah agar bisa saling berkoordinasi untuk memaksimalkan hasil belajar siswa. Berikut beberapa dokumentasi penanaman nilai karakter yang dilakasanakan menggunakan media daring kepada siswa di SMP Plus Citra Madhinatul IImi (CMI) sebagai penguatan pendidikan karakter yaitu religius, nasionalisme, integritas, mandiri, dan gotong royong.

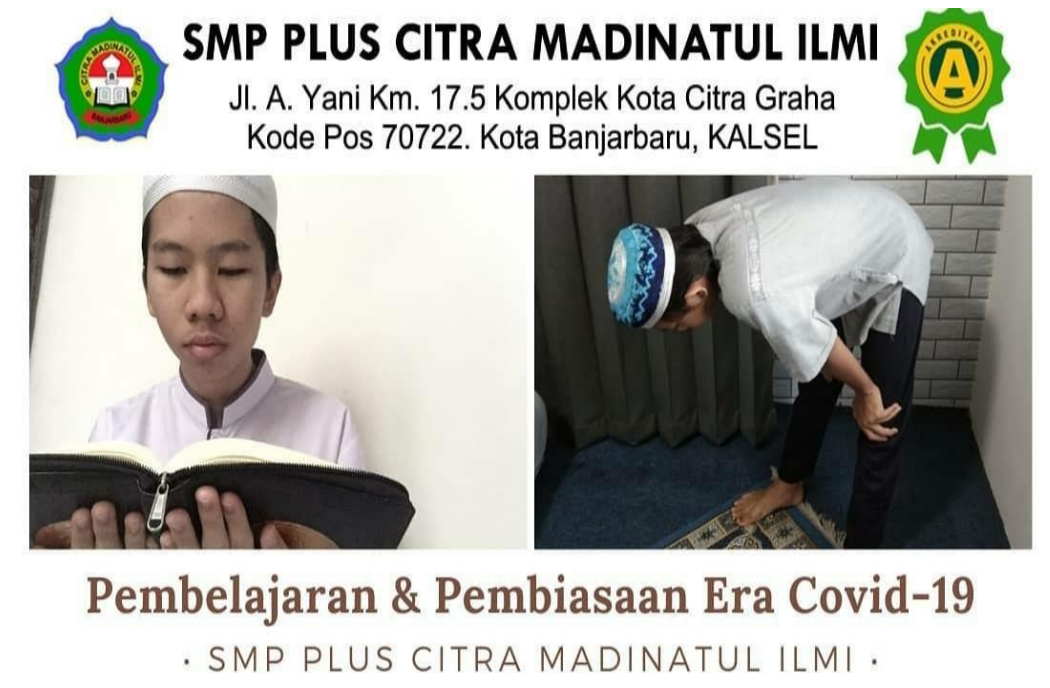

Gambar 2. Karakter Religius

Religius merupakan sikap dan perilaku yang patuh dalam melaksanakan ajaran agama yang dianutnya, toleran terhadap pelaksanaan ibadah agama lain, dan hidup rukun dengan pemeluk agama lain (Almu'tasim, 2016). Di SMP Plus $\mathrm{CMI}$, penanaman nilai religius dalam pembelajaran daring adalah dengan melakukan kegiatan kegiatan tilawah dan salat Duha oleh siswa di rumah masingmasing. Pelaksanaan kegiatan ini dimulai pukul 08.00 pagi, sebelum mata pelajaran di mulai. Kegiatan tilawah dilakukan bersama-sama melalui media Google Meet dan diawasi langsung oleh guru. Setelah selesai tilawah, siswa diminta melaksanakan salat Duha, dan melaporkan kepada guru jika sudah selesai melalui WA. 
Akhmad Syakir, Jamiatul Hamidah, Istiqamah

Pola Pendidikan Karakter Religius dalam Pembelajaran Daring SMP Plus Citra Madhinatul IImi (CMI)

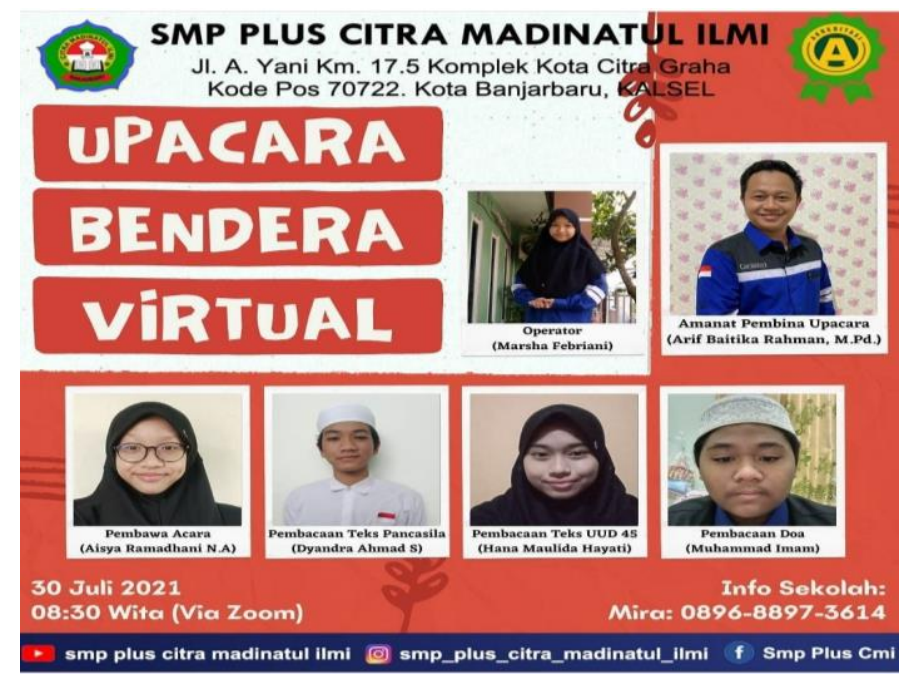

Gambar 3. Karakter Nasionalisme

Penerapan nilai nasionalisme, cara berpikir, bertindak, dan berwawasan yang menempatkan kepentingan bangsa dan negara di atas kepentingan diri dan kelompoknya dilakukan dengan upacara bendera secara virtual. Kegiatan upacara bendera masih bisa dijalankan secara virtual melalui aplikasi Zoom dan semua siswa hadir tepat waktu sesuai jam yang dijadwalkan. Bahkan pada peringatan hari kemerdekaan RI 17 Agustus 2021, SMP Plus CMI mengadakan upacara bendera secara virtual yang dihadiri oleh seluruh siswa dan guru.

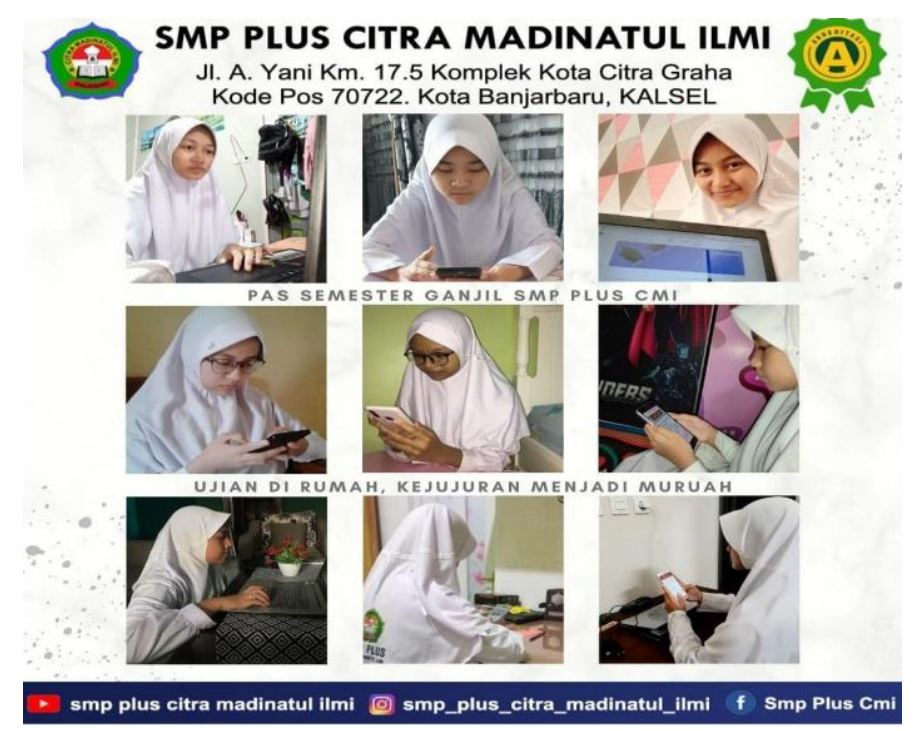

Gambar 4. Karakter Integritas dan Kejujuran

Integritas, bertindak konsisten sesuai dengan nilai-nilai dan kebijakan organisasi serta kode etik profesi, walaupun dalam keadaan yang sulit untuk melakukannya. Integritas serta kejujuran terlihat dari suasana ujian semester di sekolah. Mereka tetap diawasi oleh masing-masing orang tua yang menjadi tim

Silampari Bisa: Jurnal Penelitian Pendidikan Bahasa Indonesia, Daerah, dan Asing Vol. 4, No. 2, 2021 
Akhmad Syakir, Jamiatul Hamidah, Istiqamah

Pola Pendidikan Karakter Religius dalam Pembelajaran Daring SMP Plus Citra Madhinatul IImi (CMI)

yang bersinergi dengan wali kelas. Nilai kejujuran juga ditanamkan kepada siswa melalui tindakan mengerjakan tugasnya sendiri, bukan dilakukan oleh orang lain atau menyontek tugas yang dikerjakan oleh teman. Siswa juga diupayakan untuk menyampaikan kepada guru jika terdapat kendala dalam pembelajaran daring maupun dalam mengerjakan tugas, sehingga membentuk self confidence di dalam diri siswa.

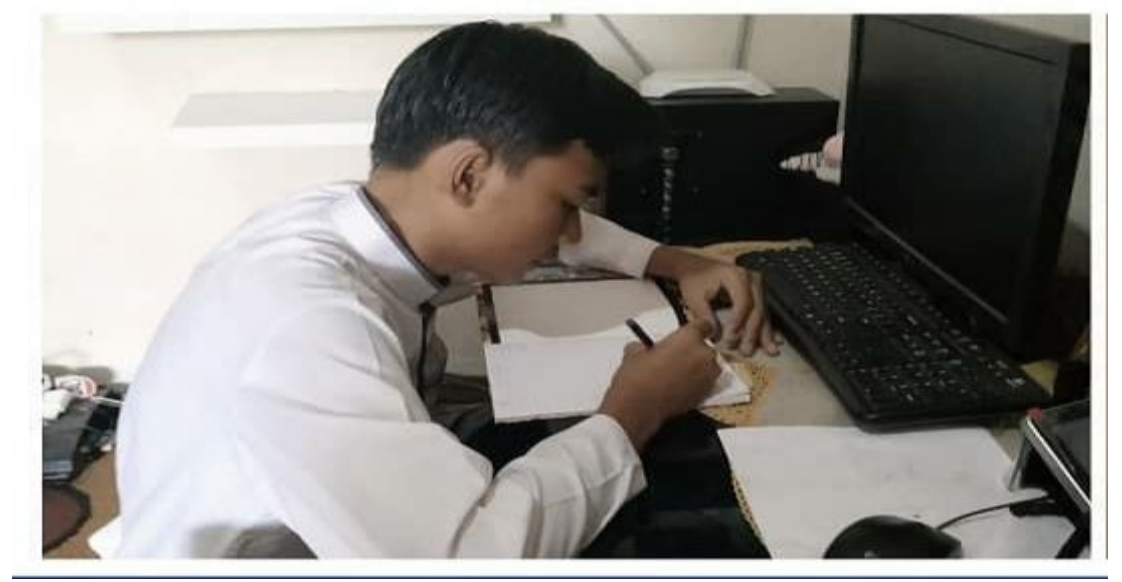

Gambar 5. Karakter Mandiri

Mandiri adalah sikap dan perilaku yang tidak mudah tergantung pada orang lain dalam menyelesaikan tugas-tugas. Siswa selalu dipantau agar tetap belajar mandiri, dan menyelesaikan tugas tepat waktu. Apabila ada siswa yang tidak mengumpulkan tugas tepat waktu, maka guru akan menanyakan langsung kepada siswa terkait kendala yang dihadapinya. Jika siswa tidak merespons, guru akan berkomunikasi kepada orang tua/wali siswa. Sebagai contoh, seorang siswa di kelas 7 tidak mengumpulkan tugasnya tepat waktu. Ketika guru/ wali kelas menanyakan melali WA, siswa tersebut tidak menjawab. Selanjutnya, guru menghubungi orang tua dan menyampaikan masalah yang terjadi. Orang tua dapat mengklarifikasi masalah yang terjadi dan mencari solusi bersama-sama dengan guru/wali kelas.

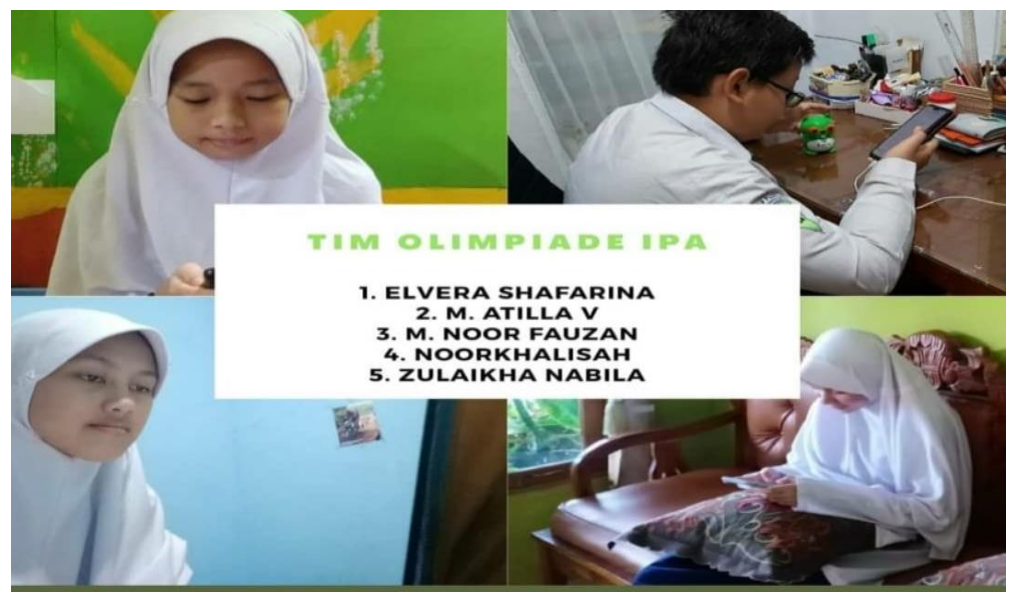

Gambar 6. Karakter Gotong Royong

Silampari Bisa: Jurnal Penelitian Pendidikan Bahasa Indonesia, Daerah, dan Asing Vol. 4, No. 2, 2021 
Akhmad Syakir, Jamiatul Hamidah, Istiqamah

Pola Pendidikan Karakter Religius dalam Pembelajaran Daring SMP Plus Citra Madhinatul IImi (CMI)

Gotong royong, bekerja bersama-sama (tolong-menolong, bantu-membantu) diantara anggota-anggota suatu komunitas. Di SMP Plus CMI, penanaman nilai gotong-royong dilakukan melalui kerja sama siswa dalam mempersiapkan diri mengikuti berbagai lomba atau kompetisi. Sebagai contoh beberapa waktu yang lalu, 4 orang siswa kelas 7 ditunjuk untuk mewakili sekolah dalam olimpiade IPA. Para siswa disiapkan dengan memberikan pembelajaran dan latihan tambahan secara daring. Keempat siswa tersebut diminta untuk melakukan koordinasi dan berkomunikasi secara efektif dalam mempersiapkan diri, sehingga ketika ada kendala, guru bisa segera menyelesaikannya. Untuk beberapa kegiatan lomba yang memerlukan latihan bersama, sekolah mengambil kebijakan meminta siswa datang ke sekolah dengan menerapkan protokol kesehatan yang ketat.

Dari uraian di atas sekolah SMP Plus Citra Madhinatul IImi (CMI) memberikan suasana pendidikan terutama dalam pendidikan karakter tetap terjaga meskipun melalui media daring. Kepala sekolah juga mengarahkan semua wali kelas dan guru mata pelajaran agar nilai karakter tetap harus terlihat dalam proses belajar mengajar. Sebagai sekolah yang sangat menjunjung tinggi nilai religius, muatan plus SMP CMI adalah islami dan berwawasan global.

\section{Simpulan dan Saran}

Pola pendidikan karakter melalui media pembelajaran daring masih bisa dilaksanakan di SMP Plus Citra Madhinatul IImi (CMI). Pola pembiasaan siswa yang sudah dilaksanakan di sekolah tetap dilakukan di rumah seperti salat Duha, disiplin masuk kelas daring, dan bertanggung jawab terhadap tugas yang diberikan oleh guru.

Media daring yang dapat menunjang penerapan pendidikan karakter di SMP Plus Citra Madhinatul IImi (CMI), seperti Zoom Meeting, Google Meet, Google Classroom. Untuk memudahkan komunikasi dengan siswa dan orang tua terkait pembelajaran bisa melalui WhatsApp. Banyak lagi aplikasi yang bisa digunakan, dengan mempertimbangkan penggunaan aplikasi yang mudah, ringan, dan hemat kuota.

Peran orang tua menjadi sangat penting untuk mendukung suksesnya pembelajaran daring. Koordinasi yang baik antara guru/wali kelas dengan orang tua/wali siswa, menjadi kunci utama terselenggaranya pembelajaran daring yang baik dan keberhasilan penerapan nilai pendidikan karakter kepada siswa. Karena penelitian ini hanya meninjau dari aspek guru dan siswa, maka disarankan bagi peneliti selanjutnya agar menggali juga dari aspek orang tua atau wali siswa. 
Akhmad Syakir, Jamiatul Hamidah, Istiqamah

Pola Pendidikan Karakter Religius dalam Pembelajaran Daring SMP Plus Citra

Madhinatul IImi (CMI)

\section{Daftar Pustaka}

Ali, A. M. (2018). Pendidikan Karakter: Konsep dan Implementasinya. Jakarta: Prenadamedia Group.

Almu'tasim, A. (2016). Penciptaan Budaya Religius Perguruan Tinggi Islam (Berkaca Nilai Religius UIN Maulana Malik lbrahim Malang). J-PAl: Jurnal Pendidikan Agama Islam, 3(1). doi:10.18860/jpai.v3i1.3994

Anggito, A. \& Setiawan, J. (2010). Metodologi Penelitian Kualitatif. In Rake Sarasin. Diambil dari https://scholar.google.com/citations?user=OB3eJYAAAAJ\&hl=en

Atmazaki, A., Agustina, A., Indriyani, V., \& Abdurahman, A. (2021). Teachers Perception of Character Education Integration in Learning Language. Jurnal Pendidikan Karakter, https://doi.org/10.21831/jpk.v10i2.32276

11(2), 149-160.

Bungin, M. B. (2005). Metodologi Penelitian Kuantitatif. Jakarta: Kencana.

Gunawan, R., Suyitno, S., \& Supriyadi, S. (2018). Nilai Pendidikan Karakter Religius dan Cinta Tanah Air Novel Rantau 1 Muara Karya Ahmad Fuadi. AKADEMIKA: Jurnal Pemikiran Islam, 23(2), 339-366. https://doi.org/10.32332/akademika.v23i2.1238

Hamirul, H. (2021). Pendidikan Karakter di Usia Dini untuk Mencegah Korupsi. Jakarta: CV. Pustaka Learning Center.

Lickona. (2018). Character Education for 21st Century Global Citizens. In Endah Retnowati (Ed.), Character Education for 21st Century Global Citizens ( $p$. 93). https://doi.org/10.1201/9781315104188

Putri, F. N. (2020). Pendidikan Karakter Siswa melalui Pembelajaran Bahasa Indonesia. Jurnal Pendidikan Bahasa Indonesia., 8(1), 16-24.

Santika, I. W. E. (2020). Pendidikan Karakter pada Pembelajaran Daring. Indonesian Values and Character Education Journal, 3(1), 8-19.

Widyastuti, O. A., Sudarmanto, E., Silitonga, B. N., Ili, L., Fransiska, S. R., Khalik, M. F., \& Silitonga, B. N. (2021). Perencanaan Pembelajaran (J. Simarmata, ed.). Buku Elektronik.

Yin, R. K. (2012). Applications of Case Study Research. New York: Sage Publication. 